\title{
A APRENDIZAGEM ORGANIZACIONAL SOB A PERSPECTIVA SÓCIO-COGNITIVA: CONTRIBUIÇÕES DE LEWIN, BANDURA E GIDDENS. ${ }^{1}$
}

\author{
LEARNING ORGANIZACIONAL UNDER PERSPECTIVE SÓCIO-COGNITIVA: \\ CONTRIBUTIONS DE LEWIN, BANDURA AND GIDDENS.
}

\author{
Christiane Kleinübing Godoi ${ }^{2}$ \\ Sandra Ferreira Freitas ${ }^{3}$
}

\begin{abstract}
RESUMO: Este artigo pretende estabelecer o translado das contribuições das teorias sóciocognitivas da aprendizagem para a esfera da aprendizagem organizacional. $\mathrm{O}$ argumento central reside na idéia de que a cognição social explica a aprendizagem organizacional de forma mais aprimorada do que os estudos fragmentados de aprendizagem originários do campo organizacional. Na perspectiva sócio-cognitiva, a aprendizagem organizacional é entendida como o resultado da reciprocidade entre construtos sócio-cognitivos e a cultura organizacional. $\mathrm{O}$ entendimento da aprendizagem organizacional passa a exigir a consideração do aspecto social da aprendizagem e a fundamentação em teorias capazes de conectar os processos individuais, o funcionamento dos grupos e as relações sociais. Dentre as teorias da aprendizagem transpassadas pelo contexto social, elegemos a análise e o translado para a esfera organizacional das seguintes teorias: a) a teoria do campo de Kurt Lewin (e sua influência sobre Dewey); b) a teoria social cognitiva da aprendizagem de Bandura (e a influência dos teóricos da atribuição); e a teoria da estruturação de Giddens.
\end{abstract}

ABSTRACT: This article seeks to establish the transfer of contributions of socio-cognitive learning theories to the sphere of organizational learning. The central argument is the idea that social cognition explains organizational learning more adequately than the fragmented studies of learning derived from the organizational field. Within the socio-cognitive perspective, organizational learning is understood as the result of a reciprocal exchange between socio-cognitive constructs and organizational culture. The understanding of organizational learning requires consideration of the social aspects of learning, and is based on theories capable of interconnecting individual processes, the functioning of the groups, and social relations. Among the learning theories that consider the social context, we elect the analysis and transfer of the following theories, to the organizational sphere: a) Kurt Lewin's field theory (and his influence on Dewey); b) Bandura's cognitive social learning theory (and the influence of the attribution theory); and Giddens' theory of structuration.

\footnotetext{
${ }^{1}$ Artigo Recebido em 05.06.2008 . Revisado por pares em 14.11.2008 . Recomendado em 11.02.2009 por Denise Del Pra Netto Machado (editora). Publicado em 22.04.2009.

Organização Responsável pelo periódico: Universidade regional de Blumenau - FURB - www.furb.br/rn
}

\footnotetext{
${ }^{2}$ Universidade do Vale do Itajaí - UNIVALI - christianekg@yahoo.com.br

${ }^{3}$ Universidade do Vale do Itajaí - UNIVALI - sandra@univali.br
} 


\section{INTRODUÇÃO}

O estudo do processo de aprendizagem organizacional constitui tema recorrente entre pesquisadores gerando muitas revisões de literatura e abordagens diversas sobre o tema. No entanto, observam-se poucos avanços da pesquisa sob a perspectiva sócio-cognitiva (ANTONACOPOULOU; CHIVA, 2007; BITENCOURT, 2006; GHERARDI, 2001; ELKJAER, 2003). Elkjaer (2001, p. 105) acredita que grande parte da literatura sobre aprendizagem organizacional é baseada em uma teoria de aprendizagem individual, ou seja, uma teoria de aprendizagem como cognição individual. Originária da teoria da aprendizagem individual, a literatura sobre aprendizagem organizacional exclui, portanto, a perspectiva social da aprendizagem, cujas teorias podem contribuir para a compreensão e o desenvolvimento da aprendizagem no campo das organizações.

Cognição social consiste em uma abordagem para a compreensão do comportamento social humano que envolve a investigação do processo mental dos indivíduos em interação com outros. Argyris; Schon (1996) alertam que a aprendizagem organizacional pressupõe a aprendizagem individual, contudo, é algo mais do que a soma das aprendizagens individuais, sendo esta condição necessária, mas não suficiente, para a cognição organizacional. Elkjaer (2001, p. 101) defende que as teorias de aprendizagem organizacional devem ter seu ponto de partida em uma teoria sócio-cognitiva, enfatizando a necessidade de reconhecer o aspecto social da cognição. Elkjaer (2001, p. 109) considera aprendizagem como uma reconstrução e reorganização de experiência que é, em essência, individual, porém baseada em uma perspectiva de indivíduos socialmente formados.

Discutindo tendências em aprendizagem organizacional, Easterby-Smith e Araújo (2001) apontam que a distinção mais significativa entre os autores que escrevem sobre aprendizagem organizacional está na concepção da aprendizagem como um processo técnico ou um processo social. Na visão técnica, a aprendizagem organizacional depende de uma correta leitura, processamento e interpretação de dados, com posteriores ações suportadas por uma interpretação lógica e racional. Na perspectiva social, entende-se que a aprendizagem é algo que emerge das interações sociais, ou seja, é socialmente construída, focalizando a maneira pela qual as pessoas atribuem significados a suas experiências de trabalho, que podem ser explícitas ou tácitas. Os autores que entendem a aprendizagem como socialmente construída, entendem também que a aprendizagem é um processo político e está fortemente entrelaçada à cultura da organização, sendo que a aprendizagem define a cultura da organização, mas ao mesmo tempo também é fruto da mesma, tornando-se limitada e influenciada pelas formas de comportamentos e práticas não-canônicas. A perspectiva social acredita que a aprendizagem é parte da cultura organizacional, pois a aprendizagem organizacional não é algo que acontece dentro da mente das pessoas, mas é fruto da interação entre os indivíduos. Esta interpretação baseia-se fortemente na constatação de que é exatamente pela socialização que novos indivíduos aprendem os padrões de comportamento na organização.

$\mathrm{O}$ foco da teoria de aprendizagem individual está no como às pessoas obtém o conhecimento e não no contexto organizacional como elemento chave para aprendizagem, socialização e desenvolvimento dos membros organizacional. Em outras palavras, a teoria da aprendizagem individual é criticada por negligenciar a dimensão ontológica da aprendizagem e somente focar a dimensão epistemológica. A importante diferença da teoria da aprendizagem social é que ela abarca tanto a epistemologia quanto a ontologia da aprendizagem (ELKJAER, 2003). 
$\mathrm{Na}$ literatura de aprendizagem organizacional, baseada na perspectiva sócio-cognitiva, a aprendizagem é parte integral da pratica diária da vida e do trabalho organizacional, não fazendo distinção de aprendizagem individual e organizacional. No pragmatismo, o conteúdo da aprendizagem deve ser entendido como o desenvolvimento da experiência humana, o que ao mesmo tempo é para conhecer sobre o mundo e tornar-se parte dele. Não é possível desenvolver experiência como um processo de conhecimento ou um processo de execução, experiência engloba ambos os processos (ELKJAER, 2003).

Os autores que consideram a perspectiva social na compreensão sócio-cognitiva (ANTONACOPOULOU; CHIVA, 2007; ELKJAER, 2003; GHERARDI; NICOLINI, 2003; DEFILLIPPI; ORNSTEIN, 2003) partem das seguintes constatações: a) a aprendizagem dos indivíduos ocorre pela interação social dentro de um contexto sócio-cultural, no qual os indivíduos participam na criação da realidade; b) o reconhecimento do papel das pessoas e o papel do contexto organizacional no processo de aprendizagem nas organizações; c) e o fato de que o conhecimento é gerado a partir das relações interpessoais e das interpretações desenvolvidas durante o trabalho.

Aprendizagem organizacional exige, portanto, considerar o aspecto social da aprendizagem (ELKJAER, 2001; DEFILLIPPI, ORNSTEIN, 2003) e fundamentar-se em teorias capazes de conectar os processos individuais, o funcionamento dos grupos e as relações sociais. Dentre as teorias da aprendizagem transpassadas pelo contexto social, elegemos a análise das seguintes teorias: a) a teoria do campo de Kurt Lewin (e sua influência sobre Dewey); b) a teoria social cognitiva da aprendizagem de Bandura (e a influência dos teóricos da atribuição); e a teoria da estruturação de Giddens. Este artigo pretende, portanto, compreender o processo de aprendizagem organizacional a partir da concepção sóciocognitiva da aprendizagem.

\section{AS PERSPECTIVAS DA APRENDIZAGEM TRANSPASSADAS PELO SOCIAL: DE LEWIN A DEWEY}

A teoria pragmática de Jonh Dewey, utilizada por Elkjaer (2001), na defesa de uma abordagem social da aprendizagem organizacional, mostra a percepção de Dewey sobre aprendizagem como uma contínua reorganização e reconstrução da experiência, sendo um processo que ocorre na interação social, de forma que o agir, pensar, fazer e conhecer são partes de um mesmo processo que é aprender.

Para Dewey o processo de desenvolvimento mental é essencialmente social e se dá pela interação e participação (DEFILLIPPI; ORNSTEIN, 2003). Dewey define aprendizagem como uma contínua reorganização e reconstrução da experiência. A aprendizagem ocorre todo o tempo e em todas as situações em que as pessoas agem e interagem, refletem e pensam. A noção de Dewey sobre aprendizagem implica em um entendimento não dualista do fazer e do conhecer, da ação e do pensamento. A separação dualista é substituída por uma continuidade entre agir e conhecer (ELKJAER, 2001, p.112). As idéias e conceitos da teoria pragmática de Jonh Dewey são utilizadas por Elkjaer (2001, p.112) para defender uma abordagem social da aprendizagem organizacional. Jonh Dewey, em sua filosofia sociológica da aprendizagem encoraja-nos a recorrer a Kurt Lewin, bem como a Albert Bandura e a Anthony Giddens na busca de uma concepção social da aprendizagem.

Contribuição importante para a perspectiva social da aprendizagem é realizada pelo psicólogo Kurt Lewin, que teve início ainda na década de 1940. Através de suas pesquisas sobre a dinâmica dos grupos, Lewin afirma que a conduta dos indivíduos em grupo é determinada pela dinâmica dos fatos e pela dinâmica dos valores que se percebe em cada 
situação, confirmando a tese de que a observação é fonte importante da aprendizagem (MAILHIOT, 1977, p. 56). As descobertas de Lewin sobre as necessidades interpessoais - via experiências que comprovaram que a produtividade e eficiência de um grupo - estão relacionadas com a competência individual, mas, sobretudo, com a solidariedade de suas relações interpessoais.

A importância do contexto, do ambiente social, no comportamento dos indivíduos em grupos, foi constatada por Kurt Lewin através das pesquisas sobre a dinâmica dos grupos, que afirmam a conduta dos indivíduos em grupo como determinada pelo contexto e percepção do indivíduo sobre o grupo. Lewin constatou que o comportamento dos indivíduos é resultado de uma dinâmica gerada independentemente das vontades individuais (MAILHIOT, 1977), sendo a dinâmica do grupo resultado do conjunto das interações dentro de um espaço psicossocial. Tal evidência implica dizer que o comportamento dos indivíduos em grupos não acontece de acordo com o esperado pelas teorias que explicam o comportamento individual, sendo o contexto componente essencial. Esta verificação de Lewin corrobora a perspectiva da aprendizagem social como possibilidade de compreensão da aprendizagem organizacional.

Para compreender ou prever comportamento, a consideração da interdependência entre indivíduo e seu meio é fundamental (LEWIN, 1965). A percepção da realidade é, em grande parte, determinada pelo que é aceito socialmente como realidade pelo grupo a que pertença o indivíduo; as ações são dependentes do ambiente, refletindo sua percepção e sentimentos em relação à segurança e estabilidade do ambiente; as ações sociais são orientadas pela percepção de realidade, auto-conceito e percepção do outro (LEWIN, 1978). Tais aspectos contextuais da relação indivíduo-grupo inerentes à teoria de Lewin indicam a dificuldade da compreensão da aprendizagem organizacional, sem uma abordagem social.

As afirmações de Mailhiot (1977, p. 50) de que os comportamentos dos indivíduos como seres sociais resultam de uma dinâmica gerada independente das vontades individuais; de que os fenômenos de grupo têm características próprias (MAILHIOT, 1977) e que toda dinâmica de grupo é resultado do conjunto das interações dentro de um espaço psicossocial (LEWIN, 1978) implica em afirmar que o comportamento dos indivíduos em um ambiente social não acontece de acordo com o esperado pelas teorias que explicam o comportamento individual. Ou seja, não se pode prescindir do contexto social, uma vez que o comportamento resultante é função do contexto (LEWIN, 1978).

A influência do ambiente social e a dinâmica das situações sociais já identificadas por Lewin como fundamental na formação e na transformação das atitudes coletivas determinam as ações e reações individuais (LEWIN, 1978; BANDURA, 1986), favorecendo algumas e inibindo outras. Para Lewin, o grupo é um todo irredutível a seus constituintes individuais (MAILHIOT, 1977, p. 52). Dentro de uma perspectiva guestáltica, não pode haver fronteiras imutáveis entre consciências individuais e um determinado meio. As atitudes coletivas bem como, as atitudes pessoais não aparecem em Lewin nem como o resultado de mecanismos exteriores às consciências, nem como atos subjetivos das consciências. Elas são segmentos de uma situação social na qual se fundem em uma mesma realidade dinâmica elementos objetivos e elementos conscientes. Comportamento e desenvolvimento dependem do estado da pessoa e de seu meio (LEWIN, 1978), e devem ser considerados como mutuamente dependentes. Para compreender ou prever comportamento, a consideração desta interdependência entre individuo e seu meio é fundamental.

A percepção da realidade e o julgamento sobre o que é real ou não são, em grande parte, determinados pelo que é aceito socialmente como realidade (LEWIN, 1978), portanto, diferem conforme o grupo a que pertença o indivíduo. As ações são dependentes do ambiente, refletindo sua percepção e sentimentos em relação à segurança e estabilidade do ambiente; as 
ações sociais são orientadas pela percepção de realidade, auto-conceito e percepção do outro. Modificação da ação social do indivíduo significa, assim, alterar a percepção social do indivíduo.

Com esses argumentos, Lewin cunha a noção de campo social, como sendo um espaço onde as pessoas, os objetos, as instituições, os grupos e os acontecimentos sociais são elementos das situações sociais, que mantêm entre si relações dinâmicas (LEWIN, 1978). Mailhiot (1977, p. 54) afirma que, para Lewin, o campo social é uma gestalt, ou seja, um todo que não pode ser reduzido aos subgrupos que nele coexistem ou aos indivíduos que dele fazem parte. Analisando experiências Lewin (1978), observa-se que é geralmente mais fácil mudar indivíduos num grupo do que mudar cada um separadamente, porque não mudando os valores do grupo, o indivíduo resistirá mais fortemente às mudanças quanto mais deva afastarse dos padrões do grupo, mas se o próprio padrão do grupo é modificado, a resistência é eliminada. Quando a decisão de mudança é do grupo, a mudança individual é facilitada e estimulada (LEWIN, 1978), bem como a decisão individual de mudança é menos provável, caso não tenha sido uma decisão do grupo, concluindo-se que uma importante causa da resistência à mudança está na relação entre o indivíduo e o valor dos padrões do grupo.

O grupo constitui a base para as percepções, ações e sentimentos do indivíduo, mais do que as características mentais do mesmo (LEWIN, 1978). O grupo a que pertence o indivíduo tem ligação inevitável, íntima e dinâmica sobre o curso de vida do mesmo. Transformar indivíduos inseridos em um contexto social, somente é possível pela mudança do grupo (contexto). O nível de aspiração e os objetivos que um indivíduo se propõe é fortemente influenciado pelos padrões sociais do grupo a que pertence ou objetiva pertencer. O grupo que a pessoa faz parte influencia seu comportamento, caráter e ação, determinando seus ideais de acordo com os objetivos e expectativas do grupo ao qual está vinculada. A atmosfera do grupo, contexto social, é de grande influência sobre o indivíduo, principalmente em momentos de perigo e insegurança (LEWIN, 1978).

A indivisibilidade entre indivíduo e organização, defendida pela perspectiva social da aprendizagem organizacional é evidenciada pela noção de campo social de Lewin. GarciaRosa (1974, p. 62) entende que Lewin concebe a noção de campo social como sendo o grupo e seu ambiente, uma vez que a afirmação de que o grupo é constituído pela soma de seus membros não faz sentido para Lewin, pois um grupo possui uma estrutura e um sistema de relações próprias com outros grupos. Um grupo é um todo dinâmico que tem suas propriedades que são diferentes das propriedades de suas partes ou da soma de suas partes (LEWIN, 1965), portanto, constitui uma entidade diferente, com comportamentos também diferentes, seguindo regras e padrões diferentes do comportamento individual.

A interdependência dinâmica entre os membros é característica essencial de um grupo e não a semelhança entre os mesmos (LEWIN, 1965). Afirmar que a essência de um grupo é a interdependência dinâmica entre seus membros significa concebê-lo como um todo dinâmico, e que uma mudança realizada em uma de suas sub-partes vai refletir-se sobre todas as outras sub-partes, mudando seus estados. O comportamento do grupo é resultante das diversas forças que atuam dentro de um contexto amplo (LEWIN, 1978), assim a compreensão somente é possível pela análise que considere a influência e a existência destas forças no grupo (campo).

As influências sociais atuam em todas as ações do indivíduo e Lewin (1978), por seus experimentos, verificou que o nível de aspiração de um indivíduo é fortemente influenciado pelo seu contexto e suas experiências diretas ou indiretas. A maioria dos indivíduos tendem a manter seus padrões de comportamento bem próximo dos padrões do grupo, tanto pela necessidade de pertencer quanto pelas pressões dentro do grupo que impedem que seus membros possam divergir significativamente dos padrões estabelecidos. Toda e qualquer ação 
planejada para alguma mudança de comportamento de indivíduos em organizações deve considerar as forças do grupo que podem potencializar o processo de mudança ou impedi-lo.

A visão de Lewin sobre a dinâmica dos grupos (LEWIN, 1978) e a noção de campo social (LEWIN, 1978) como um todo indivisível, afiança a teoria da estruturação de Giddens e suas conseqüências para uma perspectiva social da aprendizagem organizacional, quando é necessário considerar a inevitabilidade das conseqüências da interação e da interdependência entre os indivíduos e as organizações sociais.

\section{TEORIA SOCIAL COGNITIVA DA APRENDIZAGEM: BANDURA E OS TEÓRICOS DA ATRIBUIÇÃO}

A abordagem da cognição social tenta entender como os aspectos do conhecimento social afetam nossas atitudes e comportamentos (inferências, julgamentos e decisões) nas diversas situações sociais e como propiciam mudanças em nosso conhecimento (TENBRUNSEL et al., 2004). Na teoria da aprendizagem social, a aprendizagem é um caminho para desenvolvimento da identidade, uma forma para ser e tornar-se parte do mundo e das organizações (ELKJAER, 2003), e quando mudamos o conteúdo da aprendizagem de aquisição de conhecimento para formação de identidade expandimos o conceito de aprendizagem para incluir uma dimensão ontológica.

Um importante teórico que justifica a abordagem social da aprendizagem organizacional é Albert Bandura, defensor da teoria de aprendizagem social ou, de forma mais abrangente, da teoria cognitivo-social. Conforme Azevedo (1997) trata-se de uma teoria de aprendizagem que considera a perspectiva comportamentalista, mas destaca alguns aspectos do comportamento que escapavam à abordagem ortodoxa comportamentalista, tais como os comportamentos resultantes da experiência, observação e da imitação. Bandura e Walters (1978, p. 16) defendem que a aprendizagem via observação acelera a aprendizagem, além de evitar as possíveis conseqüências negativas da experiência direta, já que as ações que geram conseqüências positivas tendem a permanecer e as que geram negativas tendem a desaparecer. A teoria de aprendizagem social de Albert Bandura (BANDURA; WALTERS, 1978) que destaca a aprendizagem via experiência, observação e imitação, também percebe a aprendizagem como um processo desenvolvido na interação social, de forma que as ações das pessoas são também influenciadas por estímulos de seu ambiente social (BANDURA, 1986).

$\mathrm{Na}$ teoria da aprendizagem social, desenvolvimento e aprendizagem são processos inseparáveis (GHERARDI; NICOLINI, 2003, p. 35), e complementam um ao outro, na compreensão da aprendizagem como participação em processos sociais (ELKJAER, 2003). A mudança organizacional fica comprometida quando se busca a mudança somente através da compreensão e do estímulo da aprendizagem individual, sem entender e analisar as influências das relações interpessoais no desempenho organizacional, afirma Elkjaer (2003).

Uma teoria de aprendizagem social na aprendizagem organizacional permite focar a aprendizagem que ocorre fora da mente individual e dentro do contexto organizacional, como um espaço para a aprendizagem. Isto significa que as ações organizacionais dirigidas para desenvolver a aprendizagem organizacional não podem unicamente ser direcionadas à mudança da maneira de pensar dos indivíduos, mas devem ser focalizadas no contexto organizacional, em seus padrões da participação e interação (ELKJAER, 2003). Mesmo porque a perspectiva social da aprendizagem organizacional entende que a aprendizagem é uma atividade como qualquer outra dentro da organização, estando intrínseca nas atividades que sustentam a organização (GHERARDI; NICOLINI, 2003, p. 53). 
A razão para aplicar uma teoria de aprendizagem social é que os indivíduos são diferentes entre si e que a aprendizagem pela mudança de suas maneiras de pensamento, não é a única maneira de aprendizagem, e mesmo quando esta mudança de pensamento ocorre, será sempre diferente de um individuo para outro. As organizações consistem em pessoas reais, cada uma com suas experiências, história e expectativas para o futuro; o que forma o contexto organizacional junto com a prática específica do trabalho, os artefatos ou as regras e os regulamentos organizacionais. $\mathrm{E}$ é deste ponto que aprendizagem e aprendizagem organizacional acontecem (ELKJAER, 2003).

$\mathrm{Na}$ visão cognitivo-social, as ações das pessoas são também influenciadas por estímulos de seu ambiente social. Esta teoria entende as ações humanas como resultadas de uma interação constante entre comportamentos, cognição e eventos ambientais. A teoria de aprendizagem cognitivo-social de Bandura (1986) entende que aprendizagem ocorre fundamentalmente pela observação dos modelos, e das conseqüências observadas. Comportamentos e atitudes que foram julgadas como adequadas, tendem a ser imitadas. Pela perspectiva da cognição social a natureza humana é caracterizada por uma grande potencialidade que pode ser modelada de diversas formas pela experiência direta e observacional (BANDURA, 1986, p.21).

A teoria da aprendizagem social de Bandura (1986) afirma que é no contexto das interações sociais que se aprendem comportamentos que nos permitem viver em sociedade e desenvolver capacidades especificamente humanas (como ler, escrever, falar, etc). A aprendizagem social desenrola-se ao longo de toda a vida, através do processo de socialização. Significa dizer que um indivíduo desenvolve-se através da observação, identificação e imitação de um modelo, isto é, uma pessoa pode adquirir um comportamento novo observando e imitando outras pessoas. Sob esta perspectiva as ações das pessoas, são influenciadas basicamente pelas capacidades de simbolização, capacidade de previsão, capacidade vicárias (abstração sob exemplos), capacidade regulatória e capacidade de autoreflexão (BANDURA, 1986, p. 18).

A capacidade de simbolizar provê múltiplas formas de o indivíduo alterar e adaptar seu ambiente. Pelos símbolos as pessoas transformam experiências em modelos internos para guiar futuras ações. Por símbolos atribuem significado e forma para experiências da vida. Pelos seus conhecimentos e o poder de simbolização, as pessoas podem encontrar novas formas de agir. Simbolicamente, as pessoas podem analisar as possíveis soluções. Uma capacidade cognitiva avançada juntamente com uma habilidade de simbolização permite que as pessoas criem idéias que transcendam suas experiências sensoriais (BANDURA, 1986, p. 18). Por meio de símbolos, as pessoas podem comunicar suas experiências a outras mesmo distantes do evento no tempo e no espaço.

A capacidade de premeditação (previsão) permite às pessoas não reagirem simplesmente ao ambiente imediato e nem serem simplesmente guiadas pelo passado, permite que as pessoas antecipem as conseqüências de suas possíveis ações, determinem objetivos para si e planos de ações. Por exercício da previsão as pessoas motivam-se a si mesmas e guiam suas ações (BANDURA, 1986, p. 19). Eventos futuros não podem servir como determinantes do comportamento, mas sua representação cognitiva pode ter um forte impacto causal na ação presente. Imagens desagradáveis do futuro mudam nosso comportamento; pela representação simbólica do resultado previsto pessoas podem alterar as conseqüências futuras. A previsão é produto da capacidade de reflexão.

A capacidade vicária permite a aprendizagem pela observação do comportamento de outras pessoas e suas conseqüências. A capacidade para aprender por observação permite as pessoas gerar e regular seus padrões de comportamento sem ter que passar pelo processo de 
tentativa e erro. A aceleração do processo de aquisição por aprendizagem observacional é vital para o desenvolvimento e a sobrevivência (BANDURA, 1986, p. 20), evitando erros ou conseqüências fatais. Normas sociais, estilo de vida e praticas institucionais são exemplos de aprendizagem de comportamento que se beneficiam da aprendizagem pela observação de modelos. O observador tenderá a repetir o comportamento de seu modelo quando as conseqüências de tal comportamento forem positivas.

A capacidade auto-regulatória permite a avaliação e a comparação entre os conhecimentos, padrões adquiridos e resultados de suas ações, o que gera um auto-ajuste dos padrões de comportamento, influenciando as ações futuras. A capacidade de auto-reflexão é a capacidade de refletir conscientemente sobre suas ações, o que permite as pessoas analisarem suas experiências e pensarem sobre seus processos. Pela reflexão sobre suas várias experiências e conhecimentos, as pessoas podem gerar novos conhecimentos, alterando suas concepções sobre si mesmo e o mundo.

A ação pessoal nem sempre é objetivamente racional. Racionalidade depende da habilidade de argumentação nem sempre bem desenvolvida ou usada efetivamente. As pessoas falham ao fazer julgamentos baseados em inferências ou informações inadequadas ou por não considerar todas as conseqüências ou diferentes opções. Alem disso, exemplos errados e interpretações equivocadas dos eventos levam a concepções errôneas sobre si mesmo e sobre o mundo (BANDURA, 1986, p.22). A teoria cognitivo-social de aprendizagem traz em si concepções e fundamentos essenciais para uma melhor compreensão da aprendizagem organizacional e de suas conseqüências e possibilidades para o mundo da gestão.

A teoria da atribuição é uma das áreas de pesquisa do campo da cognição social, que estuda como as pessoas elaboram explicações causais a respeito dos eventos, e como essas atribuições causais influenciam as expectativas futuras, o autoconceito e a auto-estima (BECK, 2001). Os teóricos da Teoria da Atribuição como Heider (1958) pressupõem que o homem é motivado para descobrir as causas dos eventos e entender seu ambiente, e presumem que as relações que estabelecemos (acreditamos), existentes entre o indivíduo e o meio ambiente influem em nossa forma de nos comportarmos (BECK, 2001).

A teoria da atribuição, por sua vez, trata sobre a maneira como as pessoas associam comportamento com causas específicas, e as explicações do dia-a-dia e do senso comum que os indivíduos constroem para eventos sociais ou ações realizadas por outras pessoas (TENBRUNSEL et al., 2004) e teorias. Nesse campo examina-se como o agente da percepção social (perceptor) acumula, combina e usa informação para chegar a explicações causais de eventos (FISKE e TAYLOR apud TENBRUNSEL et al. (2004). As explicações causais e as expectativas em relação aos eventos influenciam as ações dos indivíduos. As relações e causas atribuídas a um evento ou situação pelo individuo influenciam fortemente suas ações futuras, constituindo-se como fundamental nos processos de aprendizagem.

Para Rodrigues apud Beck (2001), na concepção de Heider, o homem tem necessidade de descobrir as causas dos acontecimentos e entender seu ambiente, fazendo atribuições à objetos e eventos, buscando uma realidade mais estável, previsível e controlável. Jones; Nisbett apud Beck (2001) identificaram a tendência dos indivíduos ao fazerem atribuições a comportamentos de forma diferenciada ao avaliar suas próprias ações ou a de outros, ou seja, quando observamos o comportamento dos outros tendemos a atribuir-lhes causalidade pessoal. Ao analisarmos o nosso próprio comportamento, atribuímos seu surgimento mais a causas externas.

Rotter, mesmo não sendo teórico da teoria da atribuição, desenvolveu uma teoria de aprendizagem social na qual postulava que a tendência a realizar algum comportamento é, em 
parte, função da expectativa de que a resposta será seguida de reforço (AZEVEDO, 1997). E Segundo Rotter, esta expectativa pode ser específica, baseada na contingência entre a resposta e o reforço, ou seja, que o comportamento do sujeito (resposta) é a causa do reforço, ou uma expectativa generalizada, que é a crença relativa à probabilidade de reforço para uma classe de comportamentos relacionados entre si (BECK, 2001). A tendenciosidade auto-servidora que representa a tendência em atribuir nossos fracassos a causas externas e nossos sucessos a internas, se fundamenta na preservação da auto-estima e autoconceito, e numa certa sensação de controle (BECK, 2001).

Fontes importantes de tendência atribucional são os esteriótipos, rotulações e preconceitos. Os esteriótipos são crenças sobre características pessoais que formulamos em relação a indivíduos e grupos, e estão na base do preconceito e da discriminação. Tais efeitos nas relações interpessoais e intergrupais da atribuição de características à indivíduos ou grupos, tem preocupado estudiosos (TENBRUNSEL et al., 2004) devido às questões de conflito e correlação ilusória. Os rótulos são atribuídos aos outros para facilitar a previsão de seus comportamentos e nossa forma de agir com eles. A atribuição de um rótulo a uma pessoa nos predispõe a pressupor comportamentos compatíveis com o rótulo imputado, fazendo com que comportamentos que não se harmonizem com o rótulo imposto tendam a passar despercebidos, ou seja, deturpados para se adequarem ao rótulo (RODRIGUES et al. apud BECK, 2001).

A teoria da atribuição, conforme seus autores reafirmam a perspectiva social da aprendizagem, como necessária e fundamental, principalmente quando se busca compreender a aprendizagem organizacional, aprendizagem em um espaço social, a organização, onde se espera dos indivíduos ações e reações coerentes com a teoria social.

A organização é uma estrutura social onde os indivíduos interagem, na condição de seres sociais, agindo como tais (de acordo com princípios da teoria social), capazes das mudanças almejadas pelos indivíduos, dentro das regras, rotinas e comportamentos institucionalizados. A teoria da atribuição demonstra a tendenciosidade dos indivíduos e como as atribuições causais - geradas por experiência (aprendizagem pragmática/social) própria ou pela observação de comportamento alheio (aprendizagem observacional) influenciam na expectativa e na ação dos indivíduos - reforça a significância da perspectiva da teoria da aprendizagem social para compreensão da aprendizagem organizacional.

\section{A TEORIA DA ESTRUTURAÇÃO DE GIDDENS E A PERSPECTIVA SOCIAL DA APRENDIZAGEM ORGANIZACIONAL}

O principal pressuposto da teoria da estruturação de Anthony Giddens é que a estrutura e o indivíduo (agente) conformam-se mutuamente, estimulando e limitando ao mesmo tempo as possibilidades de ação, sendo que a estrutura é tanto razão quanto objetivo da conduta cotidiana dos agentes (GIDDENS; TURNER, 1999). Para a teoria da estruturação, os agentes, a ação e a interação são limitadas e dirigidas pela dimensão estrutural da realidade social, embora também contribuam ativamente na construção e formatação desta estrutura da qual são vítimas e culpados. A noção de reflexividade da teoria social que diz que todo conhecimento é incerto e pode ser revisado a qualquer tempo (GIDDENS, 1991) mostra-se adequada quando analisamos aprendizagem organizacional sob a perspectiva social. Estas constatações de Giddens sobre as interações sociais, indicam-nos a importância da abordagem social na compreensão da aprendizagem organizacional.

Para Giddens, estrutura é o conjunto de regras e recursos implicados, de modo recursivo, na reprodução social. Constata-se, aqui, que a noção de estrutura é fundamentalmente processual, dizendo respeito a práticas padronizadas e recorrentes, que se 
encontram situadas no tempo e no espaço. Neste sentido, os indivíduos vivem e se organizam através de processos dinâmicos de interação social, ou seja, todos os homens têm potenciais que são desenvolvidos ao longo da sua vida. Entretanto, muito embora haja na conduta humana uma dimensão subjetiva considerável, também há certo limite à autonomia de ação do indivíduo: a regularidade da conduta. Logo, a conduta não é nem mecânica e nem aleatória, pois há o elemento que conduz à sua padronização no tempo e no espaço. Essa padronização também não é rígida, pois há um limiar de autonomia nas ações (ASENSI, 2006), para (GIDDENS, 1991) mesmo sendo a vida social por nós produzida e reproduzida em nossas ações, não possuímos controle completo sobre seu curso.

As concepções que predominam a respeito das relações entre indivíduo e sociedade dizem que a diferenciação das partes que gera a unidade do conjunto; porém, que o contrário também é verdadeiro. Os indivíduos convivem em sociedade, que é mais do que um somatório daqueles que a integram; mais que isso, é a sociedade, em múltiplos sentidos, que dá origem ao indivíduo. Nós fazemos a sociedade ao mesmo tempo em que somos moldados e formatados em nossas ações, comportamentos e modo de vida pela sociedade (ASENSI, 2006).

A estrutura é tanto razão quanto objetivo da conduta cotidiana dos agentes (GIDDENS; TURNER, 1999). Para a teoria da estruturação, os agentes, a ação e a interação são limitadas e dirigidas pela dimensão estrutural da realidade social, embora também contribuam ativamente na construção e formatação desta estrutura da qual são vítimas e algozes.

A dualidade da estrutura refere-se à retroatividade existente na vida social (GIDDENS apud COHEN, 1999), de forma que as ações criam a estrutura, e simultaneamente são moldadas e limitadas por esta mesma estrutura. Giddens postula uma dualidade de estrutura em que a estrutura fornece as regras e os recursos envolvidos na atuação, que também reproduz as propriedades estruturais das instituições sociais (GIDDENS; TURNER, 1999, p. 17). As práticas sociais são constantemente repensadas, iluminadas pelas conseqüências deste próprio fazer, reformando tais práticas (GIDDENS, 1991).

Considerando a teoria da estruturação, Berends et al. (2003) buscam integrar os níveis de aprendizagem (individual e organizacional) e, conforme os autores, existem quatro razões para considerar a teoria de estruturação importante para compreensão do relacionamento entre aprendizagem individual e organizacional. Primeiro, o relacionamento entre fenômenos individuais e coletivos é central na teoria da estruturação. Segundo, Giddens em sua teoria considera fundamental a capacidade de conhecimento dos indivíduos. Terceiro, a análise de Giddens da estrutura considera uma interação entre aprendizagem, poder, recursos econômicos e normas. E a quarta razão é que a teoria da estruturação considera a dinâmica da realidade social, e o processo de aprendizagem é um destes fenômenos naturalmente dinâmicos.

A teoria da estruturação busca desfazer o dualismo indivíduo versus sociedade; e o dualismo agência versus estrutura. Agência e estrutura são dois lados de uma mesma realidade social (GIDDENS, 2005, p. 532), portanto, inseparáveis. Indivíduos e estrutura se intercruzam nas práticas sociais recorrentes.

Um sistema social existe da relação reproduzida entre atores ou coletividade, organizado como práticas sociais regulares, isto faz as práticas como o domínio primário das ciências sociais. Práticas são ações recorrentes e regularizadas de indivíduos situados em um sistema social, que criam e recriam o sistema (GIDDENS; TURNER, 1999). Estruturas existem como uma propriedade das práticas sociais. Giddens (2005) esquematiza um quadro dinâmico da estrutura, como resultado e recurso para a ação, ambos limitando e favorecendo- 
A APRENDIZAGEM ORGANIZACIONAL SOB A PERSPECTIVA SÓCIO-COGNITIVA: CONTRIBUIÇÕES DE LEWIN, BANDURA E GIDDENS.

a. Estruturas são resultados da percepção enquanto são produzidas e reproduzidas na interação.

De acordo coma teoria da estruturação organizações não são mais do que práticas regularizadas de indivíduos. A aparente habilidade das organizações para agir consiste na agencia de seus membros constituintes. Berends et al. (2003) definem aprendizagem organizacional como desenvolvimento do conhecimento pelos membros organizacionais, considerando aquele conhecimento aplicável nas atividades organizacionais, o que implica em potencial para mudança destas atividades.

De acordo com a teoria da estruturação, os sistemas sociais consistem em práticas recorrentes. Assim, nós assumimos que mudanças nas atividades organizacionais consistem em mudanças nas práticas recorrentes executadas pelos membros da organização. Baseado na teoria da estruturação, supomos que o processo de aprendizagem organizacional é realizado nas práticas organizacionais, como uma forma específica de estruturação.

A perspectiva estruturacionista da aprendizagem organizacional considera $o$ desenvolvimento da aprendizagem e do conhecimento baseada nas práticas, concordando com a teoria pragmática de Jonh Dewey, que serviu de suporte para a defesa da perspectiva social de aprendizagem tal como defendida por Elkjaer (2003); Gherardi; Nicolini (2003); Antonacopoulou; Chiva (2007); Defillippi; Ornstein (2003). Ambas as perspectivas concebem aprendizagem como parte inseparável e integral das práticas sociais. O Quadro 1 propõe uma análise comparativa entre as concepções sociais aprendizagem e a aprendizagem organizacional centrada no indivíduo 


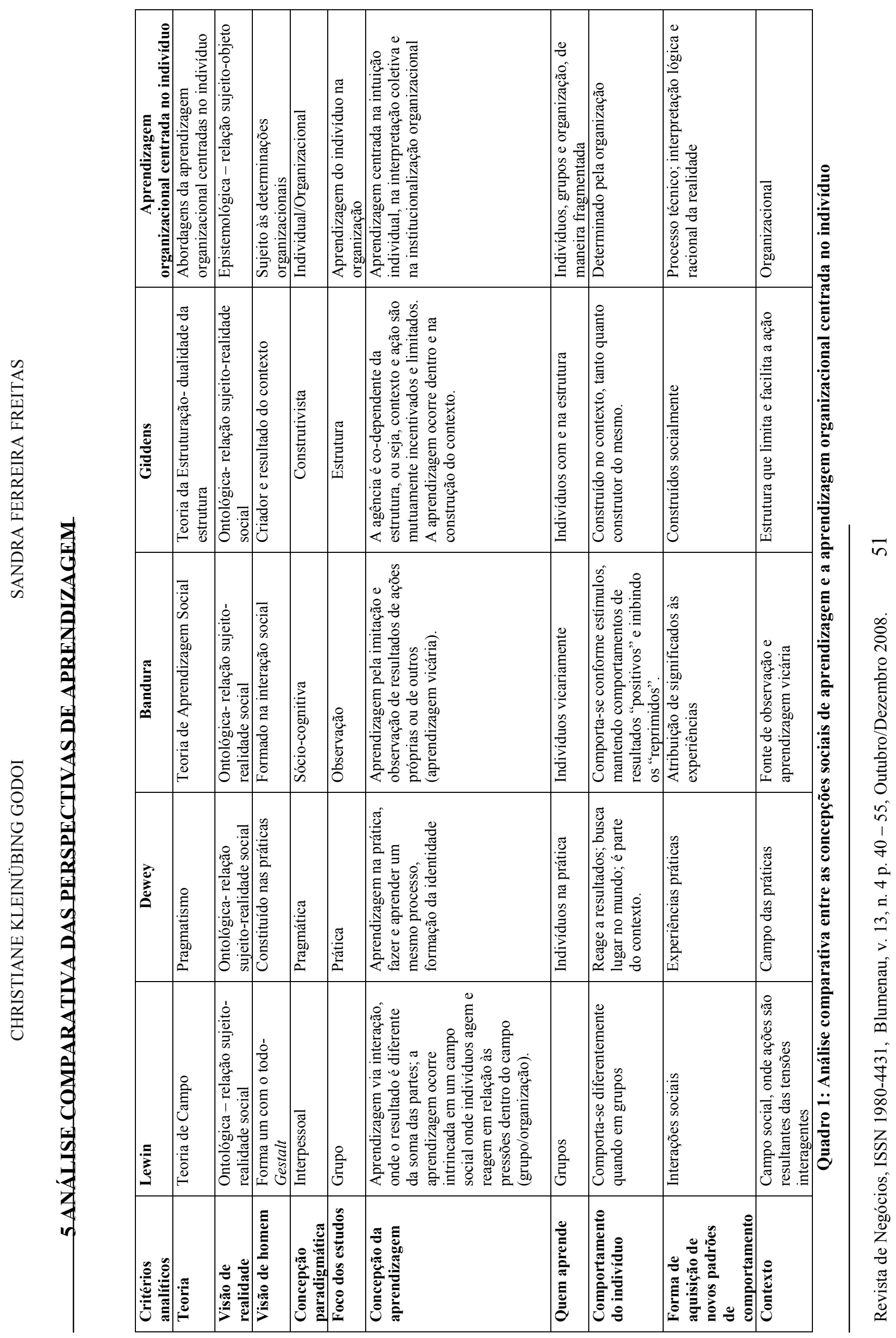


A análise comparativa dos critérios evidencia que as teorias transpassadas pela abordagem sócio-cognitiva preocupam-se e incorporam mais o caráter social da aprendizagem do que as próprias abordagens tradicionais da aprendizagem organizacional. $\mathrm{O}$ translado das teorias originárias do campo da psicologia do indivíduo para o cenário organizacional poderia contribuir para a guinada da aprendizagem organizacional para a esfera social.

Nesta perspectiva as situações, o contexto são fundamentais para a aprendizagem. Também a perspectiva da construção social inclui os princípios psicológicos da cognição social e da cognição individual para compreensão dos processos de aprendizagens.

Através desta comparação é possível assumir que os indivíduos aprendem observando outras pessoas em contextos sociais. A aprendizagem se dá através da interação com e no contexto social.

\section{CONSIDERAÇÕES FINAIS}

As perspectivas analisadas consideram a aprendizagem como situada e contextual, com distintas peculiaridades teóricas. A noção de campo social de Lewin, como sendo um espaço onde as pessoas, os objetos, as instituições, os grupos e os acontecimentos sociais são elementos das situações sociais, que mantêm entre si relações dinâmicas (LEWIN, 1965), permite-nos enxergar organizações como campos sociais. Mailhiot (1977, p. 54) afirma que para Lewin, o campo social é uma gestalt, ou seja, um todo que não pode ser reduzido aos sub-grupos que nele coexistem ou aos indivíduos que dele fazem parte, o que também implica em dizer que não poderemos compreender a aprendizagem organizacional pela compreensão da aprendizagem dos indivíduos, sem considerar o fator contexto e força do social sobre o comportamento e o desenvolvimento individual.

Experiências de Lewin (1978) indicaram que é geralmente mais fácil mudar indivíduos num grupo do que mudar cada um separadamente, o grupo constitui a base para as percepções, ações e sentimentos do indivíduo, mais do que as características mentais do mesmo (LEWIN, 1978). Assim, quando a decisão de mudança é do grupo, a mudança individual é facilitada e estimulada (LEWIN, 1978), concluindo que uma importante causa da resistência à mudança está na relação entre o indivíduo e o valor dos padrões do grupo, revelando-se o poder da estrutura sobre o comportamento social dos indivíduos.

Um grupo, que junto com o ambiente, forma um campo social, é um todo dinâmico que tem suas propriedades diferenciadas das propriedades de suas partes ou da soma de suas partes (LEWIN, 1978). Portanto, trata-se de uma entidade diferente, seguindo regras e padrões diferentes do comportamento individual. Esta idéia nos faz pensar que perspectivas que buscam a compreensão da aprendizagem organizacional por teorias da aprendizagem individual, sem considerar a interdependência existente entre os membros de um grupo, e destes com o contexto, são insuficientes para este propósito.

O nível de aspiração e os objetivos que um indivíduo se propõe é fortemente influenciado pelos padrões sociais do grupo (LEWIN, 1978), tanto pela necessidade de pertencer quanto pelas pressões dentro do grupo que impede que seus membros possam divergir significativamente dos padrões estabelecidos. A constatação de que a atmosfera do grupo, contexto social, é de grande influência sobre o indivíduo principalmente em momentos de perigo e insegurança, torna os conceitos de dinâmica de grupo e de estruturação (GIDDENS, 2005) fundamentais na compreensão dos processos de aprendizagem organizacional. Assim, toda e qualquer ação planejada para alguma mudança de 
comportamento de indivíduos em organizações deve considerar as forças do grupo que podem potencializar o processo de mudança ou impedi-lo.

O fato de considerar válida a teoria cognitiva social de Bandura (1986), que entende as ações humanas como resultadas de uma interação constante entre comportamentos, cognição e eventos ambientais, e que aprendizagem ocorre fundamentalmente pela observação dos modelos, e das conseqüências observadas, implica em solicitar uma abordagem social na compreensão da aprendizagem organizacional, quando grupos de indivíduos em organizações ligados por uma forte interdependência interagem de forma muito intensa e próxima, favorecendo a aprendizagem pela observação e pela imitação de modelos.

A teoria de Lewin sobre a dinâmica dos grupos (LEWIN, 1978) e a noção de campo social (LEWIN, 1978) como um todo indivisível e a teoria de aprendizagem social (BANDURA, 1986) afiançam a teoria da estruturação (GIDDENS, 2005) e suas conseqüências para uma perspectiva social da aprendizagem organizacional, quando é necessário considerar a inevitabilidade das conseqüências da interação e da interdependência entre os indivíduos e as organizações sociais.

Uma concepção de grande importância quando examinamos o comportamento de indivíduos ou grupos no contexto social - caso da aprendizagem organizacional - é a noção de dualidade da estrutura (GIDDENS apud COHEN, 1999) que se refere à retroatividade existente na vida social, de forma que as ações criam a estrutura e, simultaneamente, são moldadas e limitadas por esta mesma estrutura. Giddens postula uma dualidade de estrutura em que a estrutura fornece as regras e os recursos envolvidos na atuação, que também reproduz as propriedades estruturais das instituições sociais (GIDDENS; TURNER, 1999, p. 17), ou seja, as práticas sociais são constantemente repensadas, iluminadas pelas conseqüências deste próprio fazer, reformando tais práticas (GIDDENS, 1991).

Para Berends et al. (2003), o fato de o relacionamento entre fenômenos individuais e coletivos ser central na teoria da estruturação e esta teoria considerar a dinâmica da realidade social, além do fato de o processo de aprendizagem ser um destes fenômenos naturalmente dinâmicos, são razões para considerar a teoria de estruturação importante para compreensão do relacionamento entre aprendizagem individual e organizacional. Agência e estrutura são dois lados de uma mesma realidade social (GIDDENS, 2005, p. 532), portanto, inseparáveis realidade na qual indivíduos e estrutura se intercruzam nas práticas sociais recorrentes conceitos que reforçam o pragmatismo de Jonh Dewey, a teoria sobre dinâmica de grupo de Kurt Lewin e aprendizagem observacional de Albert Bandura.

A partir das argumentações de que é a partir do contexto social que a aprendizagem organizacional acontece (ELKJAER, 2003); que a qualidade das interações sociais tem forte influência sobre o desempenho de um grupo (MAILHIOT, 1977); que o ambiente social e a dinâmica das situações sociais são fundamentais na formação e transformação das atitudes coletivas, conformando as ações e reações individuais (LEWIN, 1978; BANDURA, 1986); que a natureza humana é caracterizada por uma grande potencialidade que pode ser modelada de diversas formas pela experiência direta e observacional (BANDURA, 1986, p.21); que uma organização é uma estrutura social onde os indivíduos interagem e, por certo, na condição de seres sociais, agem como tais (de acordo com princípios da teoria social), capazes das mudanças almejadas pelos indivíduos, mas dentro das regras, rotinas e comportamentos institucionalizados (GIDDENS, 2005); torna-se relevante a construção de uma concepção social da aprendizagem organizacional. A perspectiva da aprendizagem aplicada sugere que a aprendizagem é baseada na experiência direta, que a aprendizagem é mais efetiva na ação, e normalmente também requer intervenção por treinadores ou consultores para implementar práticas de aprendizagem individual e organizacional. Esta perspectiva esta associada a 
noções da aprendizagem pragmática de Dewey, de aprendizagem experiencial de Kolb (1997), do processo de aprendizagem de adultos de Mezirow (1991), Merriam e Caffarella (1999), das noções de comportamento de Lewin e Cartwright (1965) e da noção de loops de aprendizagem de Argyris e Schon (1996), levando a modelos de aprendizagem pela ação, os quais defendem que é na ação que acontece a aprendizagem quando indivíduos podem experienciar, refletir sobre suas hipóteses e resultados, testar e construir novas aprendizagens. Nesta abordagem as rotinas organizacionais são modelos mentais compartilhados, resultantes dos modelos mentais individuais, que guiam as ações organizacionais.

$\mathrm{O}$ quadro de referências da abordagem sócio-cognitiva da aprendizagem abre ao campo organizacional possibilidades de investigação empírica, fundamentalmente estudos de caso qualitativos e estudos etnográficos. Tais metodologias permitem a compreensão do comportamento social dos indivíduos em interação, bem como a interpretação do contexto que envolve a ação humana.

\section{REFERÊNCIAS}

AntOnACOPOUlOU, E.; CHIVA, R. The Social Complexity of Organizational Learning: The Dynamics of Learning and Organizing. Management Learning, V.38, n.277, p. 277-295, 2007.

ARGYRIS, C.; SCHÖN, D. A. Organizational Learning II: Theory, Method, and Pratice. [S.1.]: Addison-Wesley, 1996.

ASENSI, F. D. Teoria da estruturação e ação coletiva: uma exegese sobre a obra de Anthony Giddens. [S.1.]: 2006. Disponível em: http://www.duplipensar.net/artigos/2006Q2/anthony-giddens-teoria-da-estruturacao-e-acao-coletiva.html. Acesso em: 21 novembro 2007.

AZEVEDO, M. A teoria cognitiva social de Albert Bandura. Lisboa: Universidade de Lisboa, Faculdade de Ciências 1997. Disponível em: http://www.educ.fc.ul.pt/docentes/mazevedo/materiais/TeoriaCognitvaSocial.pdf.

Acesso em: outubro/2007.

BANDURA, A. Social Foundations of thought and action: A social Cognitive Theory. Englewood Cliffs, New Jersey: Prentice-Hall Inc., 1986.

BANDURA, A.; WALTERS, R. H. Aprendizaje social y desarrollo de la personalidad. Madrid: Alianza, 1978.

BERENDS, H.;BOERSMA,K.;WEGGEMAN, M. The structuration of organizational learning. Human Relations, v. 56, n.7, p. 1035-1056, 2003.

BITENCOURT, C.; AZEVEDO, D. O Futuro da Aprendizagem Organizacional: Possibilidades e Desafios. RAE. Edição Especial Minas Gerais, V. 46, p. 110-112, 2006.

COHEN, I. J. Teoria da estruturação e práxis social. In: GIDDENS, A; TURNER, J. Teoria Social Hoje. São Paulo: UNESP, 1999.

DEFILLIPPI, R.; ORNSTEIN, S. Psychological Perspectives Underlying Theories of Organizational Learning. In:EASTERBY-SMITH,M.; MARJONE, A. Lyles.(Org.). Blackwell Publishing Handbook of Organizational Learning and Knowledge Management. The Blackwell- 2003 
EASTERBY-SMITH, M.; ARAUJO, L. Aprendizagem organizacional: oportunidades e debates atuais. In: EASTERBY-SMITH, M.; BURGOYNE, J.; ARAUJO, L. (Coord.). Aprendizagem organizacional e organização de aprendizagem: desenvolvimento na teoria e na prática. São Paulo: Atlas, 2001. p. 15-38.

ELKJAER, B. Em busca de uma teoria de aprendizagem social. In: EASTERBY-SMITH, M.; BURGOYNE, J.; ARAUJO, L. (Coord.). Aprendizagem organizacional e organização de aprendizagem: desenvolvimento na teoria e na prática. São Paulo: Atlas, 2001. p. 100-115.

ELKJAER, B. Social Learning Theory : Learning as participation in social processes. In:EASTERBY-SMITH, M.; MARJONE, A. Lyles.(Org.). Blackwell Publishing Handbook of Organizational Learning and Knowledge Management. The Blackwell- 2003

GARCIA-ROZA, L. A. Psicologia estrutural em Kurt Lewin. 2a ed. Petrópolis Vozes, 1974.

GIDDENS, A. Sociologia. 4. ed. Porto Alegre: Artmed, 2005.

GIDDENS, A. As Consequências da Modernidade. São Paulo: UNESP, 1991.

GIDDENS, A; TURNER, J. Teoria Social Hoje. São Paulo: UNESP, 1999.

GHERARDI, S. Social Learning Theory: Learning as participation in social processes. In: SMITH, M. E.; et al (Org.). Handbook of Organizational Learning \& Knowledge. Ox Ford, 2004.

GHERARDI, S.; NICOLINI, D. The Sociological Foundations of Organizational Learning . In: SMITH, M. E.; et al (Org.). Handbook of Organizational Learning \& Knowledge. Ox Ford, 2004.

GODOY, A.S. Estudo de caso Qualitativo. In: GODOI, C.K.; BANDEIRA-DE-MELLO, R.; SILVA, A.B. Pesquisa Qualitativa em Estudos Organizacionais: Paradigmas, Estratégias e Métodos. São Paulo: Saraiva 2006.

LEWIN, K. Problemas de Dinâmica de Grupo. São Paulo: Cultrix, 1978.

KOLB, D. A. A gestão e o processo de aprendizagem. In: STARKEY, Ken (Ed.). Como as organizações aprendem: relatos do sucesso das grandes empresas. São Paulo: Futura, 1997. p. 321-341.

MAILHIOT, G. B. Dinâmica e gênese dos grupos. $4^{\text {a }}$ ed. São Paulo: Livraria duas cidades, 1977.

TENBRUNSEL, A. E.; GALVIN T.L.; NEALE M. A.; BAZERMAN M. H. Cognições em Organizações. In: CLEGG, S. R.; HARDY, C.; NORD, W. R. (Org.). Handbook de estudos organizacionais. São Paulo: Atlas, 2004. v. 3, cap. 1, p. 33-68. 